\section{Treatment of resistant pain in hypertrophic pulmonary arthropathy with ketorolac}

\author{
N Blackwell, L Bangham, $M$ Hughes, \\ D Melzack, I Trotman
}

\begin{abstract}
Pain associated with hypertrophic pulmonary osteoarthropathy (HPOA) may be extremely disabling and resistant to treatment. The successful use of ketorolac, a new non-steroidal anti-inflammatory drug, given by subcutaneous infusion is reported in two patients with uncontrolled pain caused by HPOA.
\end{abstract}

(Thorax 1993;48:401)

Hypertrophic pulmonary osteoarthropathy (HPOA) is a poorly understood syndrome most commonly associated with bronchogenic carcinoma. The arthropathy may be extremely disabling and painful and treatment is often ineffective. Specific therapy directed at the primary disease process may be successful in relieving symptoms ${ }^{12}$ but non-steroidal anti-inflammatory drugs (NSAIDs) remain the mainstay of conventional symptomatic management.

We report the successful use of ketorolac, a highly potent new NSAID, ${ }^{3}$ in providing symptom control in two patients with HPOA.

Michael Sobell House, Mount Vernon Hospital, Northwood, Middlesex HA6 2RN

N Blackwell

L Bangham

$M$ Hughes

D Melzack

I Trotman

Reprint requests to: Dr I Trotman

Received 3 March 1992 Returned to authors 11 June 1992 Revised version received 19 June 1992 Accepted 25 June 1992

\section{Case reports}

CASE 1

A 78 year old man with squamous cell carcinoma of the lung had become immobile and bedbound because of severe painful HPOA of the wrists, knees, and ankles. Radiotherapy to the affected lung (2000 cGy in five fractions), NSAIDs at full dosage (aspirin, naproxen, diclofenac, and flurbiprofen), as well as steroids and oral morphine had been unsuccessful in relieving his pain and swelling. Treatment was started with ketorolac, $30 \mathrm{mg}$ made up to $10 \mathrm{ml}$ in $0.9 \%$ saline over 24 hours by continuous subcutaneous infusion with a conventional syringe driver. Within 30 minutes his pain had completely resolved and he was able to walk unaided. Substitution of subcutaneous ketorolac after five days with oral flurbiprofen (100 mg twice daily) led to recurrence of his pain 12 hours later. Reintroduction of subcutaneous ketorolac again led to rapid symptom relief.

CASE 2

A 58 year old man with advanced inoperable squamous cell carcinoma of the lung was admitted with acutely painful HPOA of the left knee which prevented him from walking. He was already taking MST (50 mg twice daily), prednisolone and ibuprofen for pain in his chest wall and had received palliative radiotherapy (2000 cGy) to his lung. The pain in his leg did not respond to increased doses of morphine or to the addition of flurbiprofen. Following the introduction of ketorolac (60 mg subcutaneously in 24 hours) he became pain free and remained so until his death five days later.

\section{Discussion}

HPOA is a relatively uncommon cause of symptoms in patients with bronchogenic carcinoma, but can limit independence and mobility at a time when respiratory symptoms are minimal. These cases illustrate the difficulties in obtaining good pain control with conventional agents.

Although chemically related to indomethacin, ketorolac has minimal antiinflammatory activity at analgesic $\operatorname{doses}^{4}$ and has the advantage of being suitable for use by subcutaneous injection. We propose that the successful resolution of symptoms in these patients is due to the potent analgesic effect of ketorolac as other more potent anti-inflammatory agents had been ineffective by mouth. The oral form of ketorolac is still awaited in the UK and we believe that ketorolac will be an important addition to the therapeutic options available for the relief of pain in HPOA and merits further evaluation.

1 Campeau RJ, Rosales OR, Garcia OM, Correa OA. Resolution of hypertrophic pulmonary osteoarthropathy after radiotherapy in the absence of lung tumour after radiotherapy in the absence of
response. Clin Nucl Med 1989;14:454-5.

2 Davies RA, Darby M, Richards MA. Hypertrophic pulmonary osteoarthropathy in pulmonary metastatic disease. A case report and review of the literature. Clin Radiol 1991;43:268-71.

3 Litvak KM, McEvoy GK. Ketorolac, an injectable nonnarcotic analgesic. Clin Pharm 1990;9:921-35.

4 Buckley MMT, Brogden RN. Ketorolac, a review of its pharmacodynamic and pharmacokinetic properties and therapeutic potential. Drugs 1990;39:86-109. 